\title{
DETERMINAÇÃO DA FORMULAÇÃO E CARACTERIZAÇÃO DO NÉCTAR DE CAMU-CAMU (Myrciaria dubia McVaugh) ${ }^{1}$
}

\author{
Roberto N. MAEDA ${ }^{2, *}$, Lílian PANTOJA, Lucia K.O. YUYAMA ${ }^{4}$, José Merched CHAAR ${ }^{5}$
}

\begin{abstract}
RESUMO
O camu-camu é um fruto silvestre, encontrado nas margens de rios e lagos da Amazônia, com grande potencial econômico pelas suas características agronômicas, tecnológicas e nutricionais. Entretanto, seu consumo ainda é restrito, devido à alta acidez, amargor e adstringência da casca, necessitando, dessa forma, de tecnologias adequadas para o seu uso. O presente estudo teve por objetivo determinar a formulação ideal do néctar de camu-camu e avaliar as suas caraterísticas físicas e físico-químicas. Para a obtenção do néctar, foram elaboradas nove formulações com diferentes concentrações de polpa e açúcar, as quais foram submetidas ao teste de preferência de 30 provadores não treinados. Dentre as formulações testadas, a de maior preferência foi a preparada com $17,5 \%$ de açúcar e $17 \%$ de polpa, a qual apresentou valor de $\mathrm{L}_{\text {Hunter }}$ de 32,00 , $\mathrm{a}_{\text {Hunter }}$ de 3,22 e b $\mathrm{H}_{\text {Hunter }}$ de $-0,38$, ácido ascórbico de $382,07 \mathrm{mg} / 100 \mathrm{~mL}$, antocianinas de $2,51 \mathrm{mg} / 100 \mathrm{~g}$ e aceitabilidade global de $89,1 \%$. Os resultados demonstram a viabilidade tecnológica e nutricional do néctar de camu-camu por ser um produto atraente de cor, sabor, aroma, aceitabilidade e como fonte de Vitamina C.

Palavras-chave: Myrciaria dubia McVaugh, frutos da Amazônia, néctar, camu-camu, araçá.
\end{abstract}

\section{SUMMARY}

FORMULATION DETERMINATION AND CHARACTERISATION OF THE CAMU-CAMU (Myrciaria dubia McVaugh) NECTAR. Camu-camu is a wild fruit distributed throughout the banks of lakes and rivers in Amazonia, which presents a great economical potential on account of its agronomic, technological and nutritional features. Nevertheless, its consumption is still restricted due to its high acidity, bitterness, and skin astringency, thus needing the use of proper technologies for its use. The objective of the present study was to determine the ideal camu-camu nectar formulation and to assess its physical and physical-chemical characteristics. Nine formulations with different pulp and sugar concentrations, which were submitted to a preference test by a board of 30 untrained tasters, were prepared in order to obtain the nectar. Among the tested formulations, the one presenting the highest degree of preference was prepared with $17.5 \%$ of sugar and $17 \%$ of pulp, presenting values of $\mathrm{L}_{\text {Hunter }} 32.00$, $\mathrm{a}_{\text {Hunter }} 3.22$ and $\mathrm{b}_{\text {Hunter }}-0.38$, ascorbic acid $382.07 \mathrm{mg} / 100 \mathrm{~mL}$, anthocyanins $2.51 \mathrm{mg} / 100$ $\mathrm{g}$ and $89.1 \%$ global acceptance. The findings demonstrate the camu-camu nectar's nutritional and technological viability on account of its attractive colour, good tasting flavour, and pleasant aroma, as well as for being a source of vitamin C.

Keywords: Myrciaria dubia McVaugh, Amazonian fruits, nectar, camu-camu, araçá.

\section{1 - INTRODUÇÃO}

Na Amazônia existem inúmeras espécies vegetais com potencial econômico, dentre os quais destaca-se o camu-camu (Myrciaria dubia (H.B.K.) McVaugh), uma Myrtaceae, silvestre, de ocorrência nas margens de rios e lagos da Amazônia, conhecido também como caçari, araçá d'água ou sarão, dependendo da região [16]. Os frutos são globosos de superfície lisa e brilhante, de 2 a $4 \mathrm{~cm}$ de diâmetro e peso médio de $8,4 \mathrm{~g}$, coloração variando de vermelho-escuro a púrpuro-negro, quando maduros. Possui de uma a quatro sementes por fruto, sendo o mais comum de duas a três, reniforme, elipsóides, coberta com malha de fibrila [21]. Apresenta boas características agronômicas, tecnológicas e nutricionais. O interesse por

${ }^{1}$ Recebido para publicação em 25/10/2004. Aceito para publicação em 23/1/2006 (001424)

${ }^{2}$ Pós-graduando do curso Ciência de Alimentos da Faculdade de Ciências da Saúde. Universidade Federal do Amazonas (Ufam)

Rua Alexandre Amorim, 330, Aparecida-Manaus (AM)

CEP 69010-300

E-mail:rmaeda@inpa.gov.br

${ }^{3}$ Pesquisador - Coordenação de Pesquisas em Ciências da Saúde (CPCS). Instituto Nacional de Pesquisas da Amazônia (Inpa)

Avenida André Araújo, 2.936, Aleixo - Manaus (AM)

CEP 69060-001

${ }^{4}$ Pesquisador e orientador - Coordenação de Pesquisas em Ciências da Saúde (CPCS/Inpa)

${ }^{5}$ Professor e co-orientador - Faculdade de Ciências da Saúde (Ufam)

*A quem a correspondência deve ser enviada este fruto aumentou em função do seu notável conteúdo de vitamina C, apresentando de 1.600 [11] até 2.994 mg/100 g de polpa [21]. Além destas, concentrações superiores foram observadas por YUYAMA et al. [22] em frutos provenientes da região leste de Roraima, e apresentaram de 3.571 a $6.112 \mathrm{mg} / 100 \mathrm{~g}$ de polpa fresca, o que os tornam os mais ricos em vitamina $\mathrm{C}$, no mundo.

Apesar da descoberta e divulgação da alta concentração de ácido ascórbico no camu-camu e da sua adaptabilidade em terra-firme, este fruto ainda não faz parte do hábito alimentar da população amazonense, e a demanda pelas agroindústrias é baixa. Um dos fatores que contribuem para a restrição do seu consumo é o sabor muito ácido da polpa e o amargor da casca, levando à necessidade de pesquisas para o melhor aproveitamento do fruto. Uma das alternativas para a utilização deste fruto é na forma de néctar, uma bebida natural, nutritiva, pronta para o consumo e de fácil processamento. Sendo assim, este trabalho teve como objetivo estabelecer formulação para elaboração de néctar de camu-camu, bem como determinar suas características físicas e físico-químicas.

\section{2 - MATERIAL E MÉTODOS}

Os frutos de camu-camu foram provenientes da fazenda Yurican, localizada no km 100 da Rodovia AM-010, no município de Rio Preto da Eva, Amazonas. Estes foram colhidos maduros, selecionados segundo à presença de injúrias mecânicas e sanidade, lavados em água corrente, 
imersos em solução de hipoclorito de sódio 400 ppm, lavados novamente e secos ao ambiente.

Parte dos frutos foram separados (20 unidades) levados ao Laboratório de Nutrição e Fisico-química de Alimentos da Coordenação de Pesquisas em Ciências da Saúde do Inpa (LNFqA/CPCS/Inpa) e avaliados quanto às características físicas de peso, diâmetros transversal e longitudinal. As partes tissulares dos frutos (epicarpo e mesocarpo) foram analisadas quanto ao teor de umidade [2], ácido ascórbico [15], antocianinas totais e flavonóides [9].

Os frutos selecionados e lavados foram branqueados a $70^{\circ} \mathrm{C}$ por dois minutos com a finalidade de inativar enzimas oxidativas, cujo tempo e temperatura foram definidos em testes qualitativos para enzima peroxidase. Os frutos foram despolpados em despolpadeira de aço inox, malha 1,5 mm, marca Itametal, em área própria da fazenda Yurican, tomando-se todos os cuidados de higiene e sanidade. Em seguida, a polpa foi acondicionada em garrafão de vidro e mantida em caixa de isopor com gelo para transporte até o Laboratório, onde foi armazenada $\mathrm{a}-18^{\circ} \mathrm{C}$, até o momento do uso.

A polpa foi totalmente descongelada e homogeneizada para os testes de formulação do néctar e para analizes físicoquímicas de umidade, lipídio, proteína e acidez, de acordo com métodos preconizados pela AOAC [2]; pH [8]; açúcares redutores e totais [19]; ácido ascórbico [15]; compostos fenólicos [3]; antocioaninas totais e flavonóides [9].

O néctar foi obtido pela mistura da polpa, açúcar e água seguido de agitação até completa homogeneização. Em seguida foi pasteurizado a $75^{\circ} \mathrm{C}$ por $5 \mathrm{~min}$. Para escolha da melhor formulação, foram testadas diferentes concentrações de polpa e açúcar (Tabela 1). A formulação ideal foi escolhida por meio de análise sensorial empregando-se teste de preferência segundo Monteiro [13]. O teste foi realizado no Laboratório de Nutrição/CPCS/INPS. O néctar foi servido frio $\left(7-8^{\circ} \mathrm{C}\right)$ para um grupo de 30 provadores não treinados.

Para a análise sensorial, as amostras foram codificados com numeros e letras aleatoriamente. O teste foi dividido em três baterias independentes entre si, no qual, para cada concentração de polpa, foi determinada a melhor concentração de açúcar. Os preferidos de cada bateria foram selecionados para um teste final, de modo que apenas a melhor formulação fosse selecionada ao final do teste.

TABELA 1 - Composição dos néctares de camu-camu para determinação da formulação

\begin{tabular}{lccc}
\hline & Formulações & Polpa (\%) & Açúcar (\%) \\
\hline \multirow{2}{*}{ Bateria 1 } & Formulação I & 17,0 & 12,5 \\
& Formulação II & 17,0 & 15,0 \\
& Formulação III & 17,0 & 17,5 \\
\hline \multirow{2}{*}{ Bateria 2 } & Formulação IV & 20,0 & 15,0 \\
& Formulação V & 20,0 & 17,5 \\
\multirow{3}{*}{ Bateria 3 } & Formulação VI & 20,0 & 20,0 \\
& Formulação VII & 25,0 & 15,0 \\
& Formulação VIII & 25,0 & 17,5 \\
\hline
\end{tabular}

Com a formulação já definida, foi elaborado néctar em quantidade maior para avaliações de suas características físicas (cor), químicas e físico-química.

A avaliação da cor do néctar de camu-camu foi realizada utilizando aparelho X-Rite, modelo SP60, servindo para determinar os valores de 1 (luminosidade), a (vermelho) e b (amarelo). As análises do néctar em relação ao extrato seco, lipídios, proteína seguiram as recomendações da AOAC [2], sólidos solúveis e pH de acordo com IAL [8]. Realizou-se, ainda, avaliações de açúcares redutores e totais [19], ácido ascórbico [15], compostos fenólicos [3], antocioaninas totais e flavonóides [9].

As análises microbiológicas do néctar foram realizadas antes e após a pasteurização quanto a presença de bactérias mesófilas e psicrófilas, bolores e leveduras de acordo com a metodologia do ICMSF [7].

Os néctares foram avaliados, ainda, quanto a sua aceitabilidade por meio de escala hedônica estruturada de nove pontos, variando de "gostei extremamente" (9) a "desgostei extremamente" (1), de acordo com a metodologia de MONTEIRO [13]. O painel sensorial foi constituído por 70 provadores não treinados.

\section{3 - RESULTADOS E DISCUSSÃO}

Na Tabela 2, são apresentados os resultados das características físicas do camu-camu utilizados no experimento que estão de acordo com os normalmente citados na literatura para frutos nativos e/ou cultivados na Amazônia [21]. Entretanto, superiores aos citados por PINEDO [14], cujos diâmetros dos frutos coletados no Vale do Ribeira (SP) foram, em média, $0,746 \mathrm{~cm}$ ( $10 \%$ do total de frutos coletados), 1 a $2 \mathrm{~cm}$ (75\% do total de frutos coletados) e acima de $2 \mathrm{~cm}$ ( $15 \%$ do total de frutos coletados), demonstrando assim, a influência das condições ambientais e manejo no tamanho dos frutos.

TABELA 2 - Características físicas dos frutos de camu-camu oriundos de terra firme

\begin{tabular}{ccccccc}
\hline & Fruto (g) & $\begin{array}{c}\text { Mesocarpo Epicarpo } \\
(\mathbf{g})\end{array}$ & $\mathbf{( g )}$ & $\begin{array}{c}\text { Semente } \\
(\mathbf{g})\end{array}$ & $\begin{array}{c}\text { Diâmetro } \\
(\mathbf{c m})\end{array}$ & $\begin{array}{c}\text { Comprimento } \\
(\mathbf{c m})\end{array}$ \\
\hline Média & $9,21 \pm 1,63$ & $4,02 \pm 0,87$ & $2,57 \pm 0,28$ & $2,60 \pm 0,73$ & $2,57 \pm 0,27$ & $2,59 \pm 0,32$ \\
& & & & & & \\
CV $(\%)$ & 17,69 & 21,69 & 10,81 & 27,98 & 10,50 & 12,80 \\
\hline
\end{tabular}

Os resultados das avaliações químicas (umidade, ácido ascórbico, compostos fenólicos, antocianinas e flavonóides) do mesocarpo e epicarpo são apresentados na Tabela 3. Verificou-se que todos os componentes avaliados encontramse em concentrações superiores no epicarpo. Os frutos de camu-camu apresentaram boa retenção de ácido ascórbico após o processo de branqueamento, com redução de apenas 0,92\% no epicarpo e 0,21\% no mesocarpo. Verificou-se, ainda, que o teor de ácido ascórbico no epicarpo foi $88 \%$ superior em relação ao mesocarpo e que com o processo de despolpa parte da vitamina migrou para a polpa elevando 
a concentração de $1.640,57 \mathrm{mg} / 100 \mathrm{~g}$ no mesocarpo do fruto para $2.585 \mathrm{mg} / 100 \mathrm{~g}$ na polpa processada (Tabela 4). Além da extração este aumento é favorecido também pela presença de minúsculos fragmentos do epicarpo na polpa processada. RIBEIRO et al. [16] relataram concentrações de ácido ascórbico, que variaram de 2.400 a 3.000 mg/100 g no mesocarpo e até $5.000 \mathrm{mg} / 100 \mathrm{~g}$ no epicarpo, comprovando a alta concentração desta vitamina na casca.

As avaliações físico-químicas da polpa (Tabela 4), demonstram que os valores obtidos estão de acordo com os citados na literatura [5, 1, 18, 12], com exceção dos valores de compostos fenólicos, antocianinas e flavonoídes. Os frutos de camu-camu apresentaram teor de antocianinas de 181,38 $\mathrm{mg} / 100 \mathrm{~g}$ no epicarpo e 0,14 mg/100 g no mesocarpo. De forma semelhante ao ácido ascórbico, a maior concentração de compostos fenólicos e flavonóides foi constatada no epicarpo concordando com MACHEIX et al. [10] que relataram maior concentração destes compostos na casca e semente dos frutos.

Após despolpa, estes pigmentos, a exemplo do ácido ascórbico, migraram para polpa. A literatura apresenta grandes variações, podendo ser atribuído ao fato de o camu-camu ser um fruto decíduo, ou seja, os pigmentos estão, predominantemente, na casca. Logo, o método de

TABELA 3 - Teor de umidade, ácido ascórbico, compostos fenólicos, antocianinas e flavonóides no epicarpo e mesocarpo de camu-camu. Valores expressos em 100 g de matéria fresca

\begin{tabular}{lcc}
\hline & Epicarpo & Mesocarpo \\
\hline Umidade $(\mathrm{g} / 100 \mathrm{~g})$ & $88,26 \pm 0,27$ & $93,45 \pm 0,05$ \\
Acido ascórbico $(\mathrm{mg} / 100 \mathrm{~g})^{\star}$ & $3.092,62 \pm 35,11$ & $1.640,57 \pm 8,28$ \\
Acido ascórbico $(\mathrm{mg} / 100 \mathrm{~g})^{\star *}$ & $3.064,01 \pm 70,31$ & $1.637,16 \pm 12,87$ \\
Compostos fenólicos $(\mathrm{mg} / 100 \mathrm{~g})$ & $1.344,72 \pm 118,76$ & $553,58 \pm 5,10$ \\
Antocianinas $(\mathrm{mg} / 100 \mathrm{~g})$ & $181,38 \pm 10,78$ & $0,14 \pm 0,01$ \\
Flavonóides $(\mathrm{mg} / 100 \mathrm{~g})$ & $143,27 \pm 8,08$ & $0,40 \pm 0,02$ \\
\hline
\end{tabular}

*Frutos in natura. ${ }^{* *}$ Frutos branqueados

TABELA 4 - Composição físico-química da polpa de camu-camu. Valores expressos em matéria fresca

\begin{tabular}{lc}
\hline Componentes & Média \pm DP \\
\hline Umidade $(\mathrm{g} / 100 \mathrm{~g})$ & $92,65 \pm 0,03$ \\
Lipídio $(\mathrm{g} / 100 \mathrm{~g})$ & $0,05 \pm 0,01$ \\
Proteína $(\mathrm{g} / 100 \mathrm{~g})$ & $0,29 \pm 0,00$ \\
Açúcares redutores $(\mathrm{g} / 100 \mathrm{~g})$ & $2,96 \pm 0,00$ \\
Açúcares totais $(\mathrm{g} / 100 \mathrm{~g})$ & $4,47 \pm 0,03$ \\
pH & $2,64 \pm 0,01$ \\
Sólidos solúveis $\left({ }^{\circ} \mathrm{Brix}\right)$ & $6,20 \pm 0,00$ \\
Acidez $(\mathrm{g} / 100 \mathrm{~g})$ & $3,40 \pm 0,06$ \\
Ácido ascórbico $(\mathrm{mg} / 100 \mathrm{~g})$ & $2.585,40 \pm 8,41$ \\
Compostos fenólicos $(\mathrm{mg} / 100 \mathrm{~g})$ & $861,73 \pm 64,13$ \\
Antocianinas totais $(\mathrm{mg} / 100 \mathrm{~g})$ & $9,98 \pm 0,19$ \\
Flavonóides $(\mathrm{mg} / 100 \mathrm{~g})$ & $6,53 \pm 0,30$ \\
\hline
\end{tabular}

despolpa leva a uma maior ou menor extração destes compostos. O grau de maturação é outra variável que interfere na concentração deste pigmento, uma vez que frutos maduros apresentam maiores teores de antocianinas e são facilmente extraídos devido à maciez dos tecidos.

Na Figura 1, estão apresentados os resultados do teste de preferência entre as diferentes concentrações de açúcar para cada concentração de polpa. Verificou-se maior preferência para as formulações III, V e VIII, respectivamente das baterias 1, 2 e 3, correspondendo à concentração de 17,5\% de açúcar para as três formulações.

Na Figura 2, são apresentados os resultados do teste de preferência entre diferentes concentrações de polpa (17, 20 e 25\%) com concentração de açúcar de 17,5\%. Constatou-se que concentrações elevadas de polpa reduzem a preferência, pois segundo os provadores, o néctar torna-se forte, devido à alta acidez e aparecimento de leve adstringência e amargor. Características estas, que não são perceptíveis em concentração de 17\% de polpa.

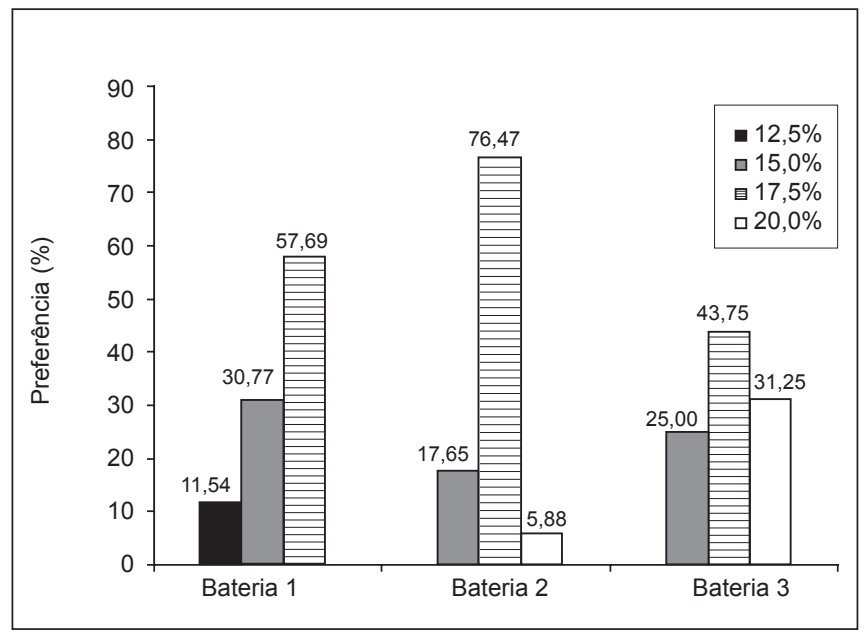

FIGURA 1 - Porcentagem de preferência dos provadores quanto à concentração de açúcar nos néctares de camu-camu com 17 (Bateria 1), 20 (Bateria 2) e 25 \% (Bateria 3) de polpa

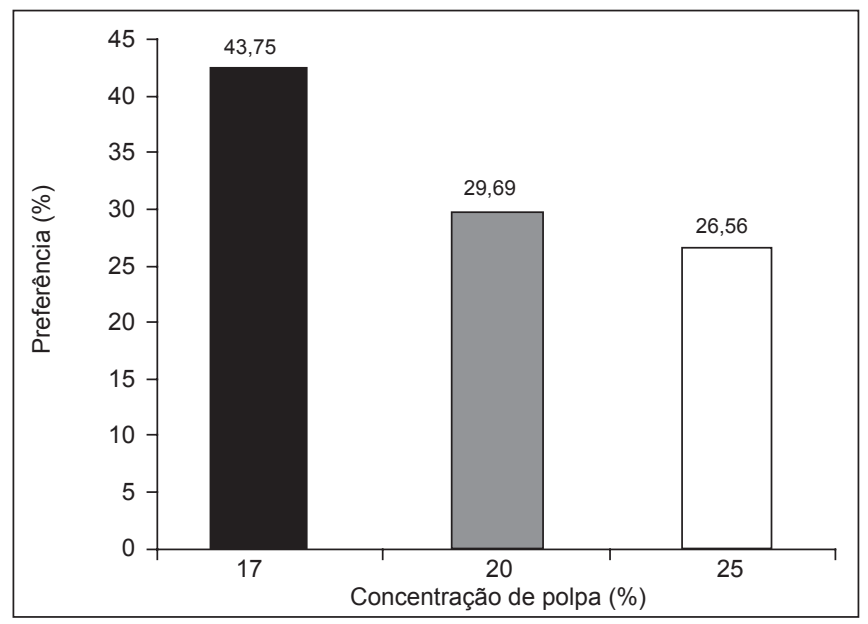

FIGURA 2 - Porcentagem de preferência dos provadores quanto à concentração de polpa no néctar de camu-camu com $17,5 \%$ de açúcar 
Na Tabela 5, são apresentadas as características físicas e físico-químicas do néctar. O valor energético do néctar devese quase que exclusivamente ao açúcar adicionado, uma vez que o camu-camu apresenta valores relativamente baixos de proteína, lipídios e carboidratos. Quanto ao conteúdo de ácido ascórbico, o néctar apresentou uma concentração de $382,07 \mathrm{mg} / 100 \mathrm{~mL}$. Considerando que a polpa utilizada apresentou $2.301 \mathrm{mg} / 100 \mathrm{~g}$, após diluição, este valor ficaria teoricamente em 391,17 mg/100 mL se não houvesse perda.

O resultado obtido demostra que a redução foi de apenas $2,33 \%$ durante o processamento, engarramento e pasteurização, evidenciando assim boa estabilidade desta vitamina no néctar de camu-camu. HENSHALL [6] cita vários fatores que podem contribuir para a estabilidade do ácido ascórbico, dentre os quais, a concentração inicial é de grande importância. Além disso, a natureza química dos frutos parece determinar a degração ou estabilidade do ácido ascórbico. Como exemplo, o autor reporta que há maior estabilidade do ácido ascórbico em suco de groselha do que em de limão, maior no suco de laranja do que no de maçã, maior no suco de abacaxi do que no de limão e maior no suco de laranja do que no de limão.

Entretanto, ainda não se conhece com exatidão esta diferença, mas supõe-se que alguns componentes naturais das frutas têm efeito inibidor sobre a degradação do ácido ascórbico. Os flavonóides, por exemplo, por meio de mecanismos de complexação, reagem com metais, impedindo que estes participem e acelerem a degradação desta vitamina. Além da complexação com metais, os flavonóides interrompem a reação em cadeia da oxidação de ácido ascórbico, agindo como receptores de radicais livres formados. Outro fator importante é o branqueamento dos frutos, eliminando dessa forma a perda do ácido ascórbico por oxidação enzimática.

Em relação ao pH, o valor obtido é importante por ser um fator limitante para o crescimento de bactérias patogênicas e deterioradoras [4], além de favorescer a estabilidade do ácido ascórbico [6], uma vez que esta vitamina tem maior estabilidade em pH ácido.

O néctar de camu-camu apresentou coloração vermelho intenso, com valores de $\mathrm{L}_{\text {Hunter }}, \mathrm{a}_{\text {Hunter }}$ e $b_{\text {Hunter }}$ de 32,00, 3,20 e -0,38, respectivamente. Entretanto, é de grande importância estudos para manutenção dessas características, uma vez que pigmentos como antocianinas, responsáveis pela coloração vermelha, pode apresentar instabilidade, especialmente quando o produto é tratado termicamente. Recomenda-se para isto a utilização de métodos como UHT que, consiste em um processo de esterilização comercial em poucos segundos, minimizando dessa forma, os efeitos negativos do tratamento térmico.

SILVA [17] verificou redução linear nos valores de $\mathrm{a}_{\text {Hunter }}$ em polpa de acerola, durante o armazenamento e atribuiu ao fato de suas polpas terem passados por dois tratamento térmicos. Esta redução dos valores de $\mathrm{a}_{\text {Hunter }}$ foram independentes do tipo de embalagem. Além disso, o autor verificou o aparecimento de coloração marrom
TABELA 5 - Características físicas, químicas e físico-químicas do néctar de camu-camu

\begin{tabular}{lc}
\hline Componentes & Média $\pm \mathrm{DP}$ \\
\hline Valor energético $(\mathrm{kcal} / 100 \mathrm{~mL})$ & $80,00 \pm 0,11$ \\
Extrato seco $(\mathrm{g} / 100 \mathrm{~mL})$ & $20,65 \pm 0,13$ \\
Lipídio $(\mathrm{g} / 100 \mathrm{~mL})$ & $0,008 \pm 0,000$ \\
Proteína $(\mathrm{g} / 100 \mathrm{~mL})$ & $0,049 \pm 0,000$ \\
Açúcares redutores $(\mathrm{g} / 100 \mathrm{~mL})$ & $1,160 \pm 0,090$ \\
Açúcares não-redutores $(\mathrm{g} / 100 \mathrm{~mL})$ & $17,91 \pm 0,04$ \\
$\mathrm{pH}$ & $2,89 \pm 0,03$ \\
Sólidos solúveis $\left({ }^{\circ} \mathrm{Brix}\right)$ & $19,93 \pm 0,32$ \\
Ácido ascórbico $(\mathrm{mg} / 100 \mathrm{~mL})$ & $382,07 \pm 3,17$ \\
Compostos fenólicos $(\mathrm{mg} / 100 \mathrm{~mL})$ & $192,04 \pm 2,50$ \\
Antocianinas totais $(\mathrm{mg} / 100 \mathrm{~mL})$ & $2,51 \pm 0,24$ \\
Flavonóides $(\mathrm{mg} / 100 \mathrm{~mL})$ & $1,11 \pm 0,05$ \\
$\mathrm{~L}_{\text {Hunter }}$ & $32,00 \pm 0,48$ \\
$\mathrm{a}_{\text {Hunter }}$ & $3,22 \pm 0,10$ \\
$\mathrm{~b}_{\text {Hunter }}$ & $-0,38 \pm 0,01$ \\
\hline
\end{tabular}

em polpas pasteurizadas, armazenadas em temperatura ambiente, mesmo utilizando o sistema higt temperature short time (HTST) e protegidos da luz. A redução da intensidade de coloração vermelho no camu-camu foi observado por PINEDO [14], avaliando polpa liofilizada armazenada em diferentes condições de umidade relativa, comprovando, assim, a instabilidade deste pigmento em produtos processados.

As avaliações microbiológicas demonstraram que o néctar não pasteurizado apresentou, para bactérias mesófilas valor

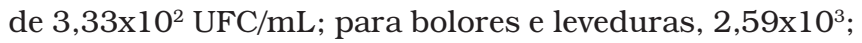
e, psicrófilas não foram detectados. A pasteurização a $75^{\circ} \mathrm{C}$ por 5 min foi suficiente para eliminar os microorganismos presentes nos néctares, pois não foram observados crescimento de microoganismos após este tratamento.

De acordo com a avaliação sensorial, o néctar elaborado apresentou aceitabilidade de $89,12 \%$ pelos provadores, em uma escala de 1 a 9 pontos. Este resultado foi superior ao obtido por SOUZA FILHO et al. [20], que também produziram néctar de camu-camu, porém com 30\% de polpa, e obtiveram baixo nível de aceitação, com pontos de 4,7 a 5 em uma escala de 1 a 9 pontos, representando 52 a $55 \%$ de aceitabilidade.

A boa aceitabilidade do néctar de camu-camu devese ao fato de se utilizar uma concentração de polpa que tormou imperceptível o sabor amargo e adstringente, porém, concentrado suficientemente para manter o sabor acentuado e característico do fruto. Outro fator determinante foi a utilização de despolpadeira, para separação da polpa, tomando-se o cuidado para que não ocorresse a trituração do epicarpo e/ou quebra das sementes, uma vez que são nestas partes tissulares que concentram a maior parte dos compostos fenólicos, responsáveis pelo amargor e adstringência. 


\section{4 - CONCLUSÕES}

A formulação ideal, nas condições experimentais testadas, foi néctar com 17\% de polpa e 17,5\% de açúcar. O néctar de camu-camu é um produto atraente em função de suas características de cor, sabor e aroma próprio do fruto, da boa aceitabilidade e ter valor nutricional como fonte de vitamina $\mathrm{C}$ natural. Portanto, um produto promissor ao mercado e agroindústria pelo seu potencial tecnológico e nutricional.

\section{5 - REFERÊNCIAS BIBLIOGRÁFICAS}

[1] ANDRADE, J.S. Curvas de maturação e características nutricionais do camu-camu (Myrciaria dubia (HBK) McVaugh) cultivado em terra firme na Amazônia Central Brasileira. Campinas. 1991177 p. Tese (doutorado em Ciência de Alimentos). Faculdade de Engenharia de Alimentos. Universidade Estadual de Campinas (Unicamp).

[2] ASSOCIATION OF OFFICIAL ANALYTICAL CHEMISTS (AOAC). Official methods of analysis. (ed) 16, Washington, 1998.

[3] CLIFFE, S.; FAWER, M.S.; MAIER, G.; TAKATA, K.; RITTER, G. Enzymes assays for the phenolic content of natural juices. J. Agr. Food Chem., v. 42, p. 1.824$1.828,1994$.

[4] FRANCO, B.D.G.M.; LANDGRAF, M. Microbiologia dos alimentos. São Paulo, Atheneu, 1996.

[5] GUTIERREZ RUIZ, A. Especies frutales nativas de la selva del Perú: estudio botánico y de propagación por semillas. La Molina. 1969. 91 p. Monografia de graduação. Universidad Nacional Agraria La Molina.

[6] HENSHALL, J.D. Ascorbic acid in fruit juices and beverage. In: Counsell, J.N.; Hornig, D.H. Vitamin C (ascorbic acid). Applied Science Publishers, London and New Jersey, 1981.

[7] ICMSF. Microorganismos de los alimentos. Técnicas de análisis microbiologico. Editorial Acribia-Zaragoza, v. $1,1983$.

[8] INSTITUTO ADOLFO LUTZ (IAL). Normas analíticas do Instituto Adolfo Lutz: métodos químicos e físicos para análise de alimentos. São Paulo, EPU, v. $1,1985$.

[9] LEES, D.H.; FRANCIS, F.J. Standartization of pigment analyses in cranberries. Hort. Science, v. 7, n. 1, p. 83-84, 1972.

[10] MACHEIX, J.J.; FLEURIET, A.; BILlOT, J. Fruit phenolics. Boca Raton, Florida, (ed.) CRC Pres, 378 p., 1990.
[11] MAEDA, R.N. Adequação tecnológica do camu-camu (Myrciaria dubia McVaugh) para produção de vinho. Manaus. 1999. 58 p. Monografia (graduação em Agronomia). Faculdade de Ciências Agrárias, Universidade Federal do Amazonas (Ufam).

[12] MAEDA, R.N.; ANDRADE, J.S. Aproveitamento do camu-camu (Myrciaria dubia) para produção de bebida alcoólica fermentada. Acta Amazônica, v. 33, n. 3, p. 489-496, 2003.

[13] MONTEIRO, C.L.B. Técnicas de avaliação sensorial. Curitiba (PR), Ceppa, $2^{\mathrm{a}}$ ed., 1984.

[14] PINEDO, R.A. Manutenção dos atributos de qualidade do camu-camu (Myrciaria dubia H. B. K. (McVaugh)) desidratado, durante armazenamento. Campinas. 2002. 96 p. Dissertação (mestrado em Engenharia Química), Faculdade de Engenharia Química. Universidade Estadual de Campinas (Unicamp).

[15] RANGANNA, S. Analysis and quality control for fruit and vegetable products. New Delhi, Tata McGraw-Hill Publishing, 1986.

[16] RIBEIRO, S.I.; MOTA, M.G.C.; CORRÊA, M.L.P. Recomendações para o cultivo do camucamuzeiro no Estado do Pará. Circular Técnica, Embrapa, Belém (PA), 2002.

[17] SILVA, M.F.V. Efeito dos diferentes tratamentos e embalagens nas características da polpa de acerola e na determinação dos teores de ácido ascórbico e das antocianinas durante o armazenamento. 1999. 224 p. Tese (doutorado em Tecnologia de Alimentos). Faculdade de Engenharia de Alimentos. Universidade Estadual de Campinas (Unicamp), Campinas, São Paulo.

[18] SILVEIRA, M.O.B.N.; BATISTA, M.T.P.M.; BAETA, M.L.M.A. Contribuição para o estudo dos alimentos industrializados. Vitamina C e conservantes. Anales Bromatológicos. v. 33, n. 1, p. 111-112, 1981.

[19] SOUTHGATE, D.A.T. Determination of food carbohydrates. Cambridge, Elsevier Science Publishers. 1991.

[20] SOUZA FILHO, M.S.M.; LIMA, J.R.; NASSU, R.T.; MOURA, C.F.H.; BORGES, M.F. Formulações de néctares de frutas nativas das regióes Norte e Nordeste do Brasil. B. Ceppa, v. 18, n. 2, p. 275-283, 2000.

[21] VILLACHICA, H. El cultivo del camu-camu en la Amazonia Peruana. Secretaria Pro Tempore del Tratado de Cooperación Amazónica. Lima, 1996.

[22] YUYAMA, K.; AGUIAR, J.P.L.; YUYAMA, L.K.O. Camucamu: um fruto fantástico como fonte de vitamina $\mathrm{C}$. Acta Amazônica, v. 32, n. 1, p. 169-174, 2002. 